\title{
Sinergias entre investigación e intervención en Trabajo Social
}

\author{
Synergies between Research and Intervention in Social Work
}

Sinergias entre investigação e intervenção no Serviço Social

Mariana Patricia Acevedo* y Maria Inés Peralta**

\section{RESUMEN}

Este artículo recoge y ordena un conjunto de análisis y propues-

Palabras

tas elaboradas a partir de la reflexión de nuestra práctica univer-

clave: práctica

sitaria en docencia, investigación y extensión. La práctica docenuniversitaria

te en grado y posgrado, ligada a prácticas de investigación y de extensión/intervención social, la dirección de tesis de trabajadores sociales y los diálogos e intercambios cotidianos con colegas y estudiantes son insumos de esta síntesis. En primera instancia, en docencia, investigación, intervención, Trabajo Social. desarrolla la cuestión de la construcción del campo disciplinar y la legitimidad profesional: luego, aborda la importancia del contexto de surgimiento de los objetos desde la producción de conocimiento y/o desde la preocupación por la intervención. En tercer lugar, intenta precisar los objetos sobre los cuales se interviene e investiga desde el Trabajo Social, para definir campos de producción de conocimientos que lo caracterizan. Las conclusiones se ofrecen como unas pocas certezas y un conjunto de desafíos desde los cuales invitamos a seguir pensando-nos.

\section{ABSTRACT}

This article collects and orders a set of analyses and proposals Key words: elaborated from our university practice in teaching, research and outreach. This synthesis includes input from the teaching practice in the undergraduate and postgraduate programs linked to research and outreach/social intervention practices, social work

University Practice in Teaching, Research, Intervention, Social Work

Argentina, docente universitaria y secretaria académica de la Facultad de Ciencias Sociales, Universidad Nacional de Córdoba. E-mail: pacevedo@coop5.com.ar ** Argentina, docente universitaria y decana de la Facultad de Ciencias Sociales, Universidad Nacional de Córdoba. E-mail: mariainesperalta50@gmail.com 
thesis advisory and the dialogues and daily exchanges with colleagues and students. This article is organized as follows: first we develop the topic of the construction of the disciplinary field and its professional legitimacy. Secondly, we address the importance of the context in which objects emerge from the production of knowledge and/or from the concern for intervention. Finally, we attempt to specify the objects of social work intervention and investigation in order to define its characteristic fields of knowledge production. Our conclusions are offered as a few certainties and a set of challenges from which social work must continue to be rethought.

\section{RESUMO}

Este artigo reúne e organiza um conjunto de análises e propostas

Palavraselaboradas a partir da reflexão de nossa prática universitária em chave: prática docência, pesquisa e extensão. A prática docente em graduação universitária e pós-graduação, ligada às práticas de pesquisa e de extensão/ intervenção social, a orientação de teses de assistentes sociais e os diálogos e intercâmbios diários com colegas e estudantes são insumos para esta síntese. Primeiramente, é desenvolvida a em docência, pesquisa, intervenção, Serviço Social. questão da construção do campo disciplinar e da legitimidade profissional. Em seguida, aborda-se a importância do contexto de surgimento dos objetos a partir da produção de conhecimento e/ou desde a preocupação pela intervenção. Em terceiro lugar, procura-se especificar os objetos sobre os quais se intervém e investiga desde a perspectiva do Serviço Social para definir os campos de produção de conhecimento que o caracterizam. As conclusões são apresentadas como algumas certezas e um conjunto de desafios desde os quais convidamos você a continuar sua análise. 


\section{Construcción del campo disciplinar y legitimidad profesional}

Ubicamos al Trabajo Social como una profesión de intervención fundada científicamente, que construye conocimientos desde la investigación en sus diferentes variantes. Múltiples definiciones de organizaciones del colectivo profesional y de reconocidas investigadoras del campo profesional así lo definen. La Federación de Unidades Académicas en Trabajo Social (FAUATS), desde su origen y con mayor énfasis en los últimos 15 años, considera a la investigación como aspecto constitutivo de la formación y del ejercicio profesional, lo que se plasma en diversos documentos y textos. En 1998, en Argentina, se realizó el Encuentro Académico Nacional en Paraná, cuyo eje fue “Currículum e investigación en trabajo social". En la presentación del mencionado evento académico se afirmaba que "la dimensión investigativa debe cobrar mayor importancia tanto en la formación como en la práctica profesional: Trabajo Social tiene que buscar mecanismos que le ayuden a resolver su relación históricamente conflictiva con el conocimiento para resignificar la disciplina, el oficio, para mejores intervenciones". Estas jornadas dieron origen a un texto señero para el Trabajo Social argentino y que sentó las bases con relación al proceso de debate colectivo y reformas de planes de estudios. Desde 2001, la Secretaría de Extensión e Investigación de la Facultad de Trabajo Social de Paraná, UNER, organiza las Jornadas de Investigación en Trabajo Social. Tanto la producción de los equipos de investigación de la Facultad y de otras unidades académicas, como las conferencias realizadas por los invitados especiales, componen el libro La Investigación en Trabajo Social. Esta publicación se edita de manera ininterrumpida desde 2001, acompañando cada una de las ediciones de las Jornadas, y su objetivo es reflejar el compromiso institucional con este espacio en la apuesta por la democratización del conocimiento.

En el ámbito regional, la organización que nos nuclea, la Asociación Latinoamericana de Enseñanza e Investigación en Trabajo Social (ALAEITS), en 2004, en Costa Rica, tiene su asamblea refundacional; luego de un debate profundo en Latinoamérica, con ocasión del siguiente Encuentro y Asamblea ordinaria de la Asociación, que tuvo lugar en Santiago de Chile en agosto de 2006, se incorpora el 
término "investigación" en la denominación de la Asociación. Transcribimos a continuación un texto del Documento "Conclusiones" de dicho evento:

La nueva Entidad será denominada Asociación Latinoamericana de Enseñanza e Investigación en Trabajo Social - ALAEITS y articulará la enseñanza e investigación, congregando profesores, investigadores y estudiantes de pre-grado y post-grado, del área de Trabajo Social en ámbito continental, teniendo en vista desencadenar acciones y movimientos en el sentido de: 1. posibilitar el protagonismo del Trabajo Social en los procesos políticos y sociales de América Latina y el Caribe, en articulación con los movimientos de resistencia a las formas de explotación y opresión del capitalismo, en sus nuevas formas de imperialismo, que promueven la agudización de la cuestión social, la guerra, la desconsideración a la autodeterminación de los pueblos, el ataque a los derechos humanos y sociales, la desestructuración de la organización de los trabajadores; 2. fortalecer el movimiento de resistencia al desmonte de la universidad y a la mercantilización de la educación superior en América Latina y el Caribe, reafirmando una concepción de educación pública, gratuita, laica, de calidad y socialmente referenciada; 3. estimular la investigación y la producción de conocimiento sobre la realidad latinoamericana y caribeña, y sobre el Trabajo Social en la Región; 4. fortalecer la enseñanza del Trabajo Social, propiciando la interlocución entre los proyectos académico-pedagógicos que orientan la formación profesional en los diferentes países; 5. promover e impulsar la articulación de la organización académica y político profesional de los diversos países; 6. posibilitar el intercambio académico y cultural entre docentes, investigadores y estudiantes de Trabajo Social en la Región; 7. promover y participar de organizaciones mundiales que mantengan congruente con los propósitos de la nueva entidad, particularmente con el fortalecimiento de un proyecto ético-político que impulse la promoción y exigibilidad de los Derechos Humanos y la construcción de ciudadanía. (Alaeits 2006, p. 2)

En términos de constitución histórico-colectiva, son innumerables los artículos, ponencias y eventos que abordan de manera articulada la investigación y la intervención en Trabajo Social. Textos 
múltiples abonan esta prolífica, diversa y sostenida preocupación y producción en torno a los sujetos de la intervención, las políticas públicas y el ejercicio profesional, entre otros tópicos. Además, gratifica la cantidad de jóvenes colegas que postulan y acceden a la carrera de investigadores en ciencias sociales; si bien esta es una referencia de carácter nacional, nos atrevemos a afirmar que es tendencia en la región. Por último, y en virtud de que esto se liga de manera ineludible a la producción de conocimientos, debemos imputar también el sostenido número de posgrados específicos y los aportes, que en términos de conocimiento, se realizan a través de las tesis de especialización, maestrías y doctorados.

Iamamoto sostiene que el Trabajo Social, en tanto es "una profesión volcada para la intervención en la realidad utiliza conocimientos socialmente acumulados y producidos por otras ciencias y puede y necesita producir saberes" (1997, p. 139). De este modo, siguiendo con la misma autora, es posible buscar "fundamentos científicos más sólidos que orienten la actuación, sobrepasando la mera actividad técnica“ (Iamamoto, 1997, p. 139). Por su parte, Estela Grassi afirma que "la investigación necesariamente debe estar implicada en el campo del trabajo social, como constitutiva de su práctica“ (2007, p. 28). Nora Aquín plantea tres premisas en relación con la cuestión que venimos señalando, e indica que:

Trabajo Social, en tanto profesión, interviene en la producción de conocimiento, en los procesos de reproducción de sus cuadros a través de la docencia y en la transformación de situaciones de la vida cotidiana de los sectores subalternos a través de la prestación de servicios. (Aquín, 2006, p. 9)

Sostiene que Trabajo Social se encuentra en condiciones de superar la posición binaria entre conocer y actuar, para poder pensarse a sí mismo como intérprete - desde un lugar teórico que es también político-y como experto comprometido con la realidad, y agrega: "La investigación en ciencias sociales es un campo de indagación teórica, metodológica y empírica fundamental para quienes nos desempeñamos en el campo de las ciencias sociales" (Aquín, 2006, p. 10). Así, la construcción del campo disciplinar requiere que la investigación ocupe un lugar sustantivo y que la intervención se funde en teorías relativas a los objetos sobre los que interviene. 
Las afirmaciones planteadas llevan implícito un enfoque constructivista de lo social lo que, en términos de Nora Aquín (1996 y 2000), implica reconocer que no se accede directamente a lo real sino a través de mediaciones, en las que se juegan las distintas significaciones que atribuimos al problema y que, desde estas distintas significaciones, se propone un tipo de modificación u otro. El objeto de una disciplina es el equivalente teórico de un problema que tiene existencia empírica, es un fenómeno real y concreto que, como tal, existe con independencia, pero que, dentro de la disciplina, es una construcción intelectual. Las disciplinas de intervención - al igual que las ciencias - no trabajan con objetos reales, sino con objetos construidos contra el sentido común.

Iluminar el problema de la relación teoría-práctica, del conocimiento y la acción - problema recurrente y persistente en nuestra profesión-, nos lleva a recuperar el concepto de "praxis". Karel Kosic, autor clásico al que siempre es fructífero volver para desentrañar este concepto dialéctico fundamental, afirma que el conocimiento no es contemplación ni reproducción o reflejo del mundo externo al ser humano en su conciencia, ya que ello implicaría negar la capacidad de creación del hombre, ubicándolo en un papel pasivo. Por el contrario, afirma que el hombre solo conoce "en tanto" crea la realidad, que las condiciones de dicho conocimiento son las siguientes:

...sólo conocemos el mundo, las cosas y los procesos en cuanto "los creamos", o sea en cuanto que nosotros los reproducimos espiritualmente. Pero esta reproducción espiritual de la realidad no puede ser concebida de otra manera que como uno de los diversos modos de relación humana práctica con la realidad. (Kosick, 1965, p. 244)

Por el contrario, el conocimiento moderno trató la tensión entre opuestos $-\mathrm{y}$, dentro de ello, la relación teoría-práctica - de un modo binario, concibiendo dichos opuestos como preexistentes, con autonomía y como entidades independientes, lo que es fruto de un

...pensamiento instalado en la era moderna que tiende a ocultar la unidad profunda y mantener separados los momentos, promoviendo una división social del trabajo social que ubica al universo teórico de la pura interpretación como patrimonio del "amo" y al universo práctico de la pura acción como el patrimonio del "esclavo". (Grüner, 2006, p. 108) 
La categoría de "praxis" nos lleva a abordar dialécticamente los opuestos, comprendiéndolos como mutuamente constitutivos e implicados; al decir de Cristina González:

...en términos generales, una teoría de la praxis sostiene que la verdad última sobre los hechos no puede ser conocida por adelantado, que el conocimiento emerge en el contexto de las prácticas sociales y, por lo tanto, es contingente histórica y contextualmente. La relación entre teoría y práctica es infinitamente dialógica: la teoría toma las luchas presentes como su premisa y trabaja para ayudar a crear capacidad para la reflexión crítica. (Gonzalez, 2007, p. 41)

Desde esta concepción de praxis, entendemos que el Trabajo Social, en tanto disciplina de las Ciencias Sociales, construye, fundamenta y diseña mediaciones conceptuales desde las cuales comprende, identifica y precisa tanto los límites como las posibilidades que cada contexto histórico ofrece para la intervención profesional. Al decir de Iamamoto, dichos límites y posibilidades:

...no se traducen inmediata y mecánicamente a la órbita profesional. Se encuentran sujetas a un sinnúmero de mediaciones que deben ser apropiadas y elaboradas por los agentes profesionales - tanto en el ámbito de la producción intelectual como en el ámbito de las estrategias de intervención- para que recién ahí puedan asumir la forma de respuestas teóricas y técnico-políticas a las demandas emergentes en aquel campo de posibilidades. (Iamamoto, 2003, p. 222)

Las reflexiones epistemológicas que el Trabajo Social se aportó sobre su campo disciplinar adquieren un lugar preponderante en el periodo histórico de la reconceptualización ${ }^{3}$. Las producciones del CE-

\footnotetext{
Gustavo Parra afirma que las expresiones y producciones en torno al estatuto científico del Trabajo Social durante la reconceptualización son múltiples y su reconstrucción demandaría un trabajo que excede las intenciones del presente artículo. De cualquier manera, consideramos pertinente señalar que es durante la reconceptualización que se instala la discusión y el análisis sobre el carácter científico de la profesión, y que es en este proceso de búsqueda del estatuto que se establece el debate acerca del método y su objeto. En síntesis, dice Parra, la referencia a la cientificidad del Trabajo Social, a la definición de su método y de su objeto, nos remite a una discusión epistemológica sobre el Trabajo Social.
} 
LATS y, en particular, de la Revista Acción Crítica, concentran en gran parte dichas reflexiones y debates.

Reconociendo este momento de inflexión en la profesión, y a partir de algunos de los debates que se instalaron con fuerza en el colectivo profesional y permearon nuestra formación y posterior ejercicio como docentes e investigadoras, nos interesa en este artículo recuperar algunas discusiones sobre la constitución y fundamentación histórica del campo disciplinar del Trabajo Social que tuvieron lugar en la Escuela de Trabajo Social de la Universidad Nacional de Córdoba, y también en otras unidades académicas de Argentina, desde la recuperación democrática en adelante, y en las cuales fueron centrales los aportes del profesor Alberto Parisí .

Los ejes articulados que el profesor Parisí nos proponía para analizar el campo profesional eran los siguientes:

1. ¿Cómo se constituye el Trabajo Social como profesión?

2. ¿Cómo se constituye el objeto de intervención del Trabajo Social?

3. ¿Cuál es el alcance y validez de los conocimientos científicos que componen el cuerpo teórico del Trabajo Social y cuál la relación de éstos con la ideología?

Respecto del primer punto, relativo a la constitución de la profesión, tres componentes conforman la totalidad del campo disciplinar: el práctico, el teórico y el ideológico ${ }^{5}$. El práctico, en tanto hay intervención, acción, sobre la realidad, aplicación de técnicas y procedimientos; el teórico se evidencia en el reconocimiento de un conjunto de conocimientos necesarios para quienes ejercen el oficio, y que se expresan en el currículo a través de asignaturas de las ciencias sociales en general y de la intervención social en particular; el ideológico refie-

\footnotetext{
$4 \quad$ El profesor Alberto Parisí ha sido un referente fundamental en las reflexiones epistemológicas y disciplinares del Trabajo Social en Argentina, especialmente valorado en las carreras de Trabajo Social de la UNC, de la UNER, de la UNLP, las que, luego de la recuperación democrática, asumieron un papel central en la rehabilitación de debates acerca de la reconceptualización, mismos que quedaron truncos en el contexto dictatorial argentino.

5 Podemos encontrar en estos tres componentes que identificaba el profesor Parisí, el antecedente de las tres dimensiones (técnico-instrumental, teórico-ideológica y éticopolítica) que años después fueron reconocidas en nuestros debates sobre el campo profesional.
} 
re a las valoraciones sobre la realidad social, que más que diferenciar al Trabajo Social de otras prácticas sociales, lo identifica con ellas.

Reconociendo estos tres componentes de la práctica profesional y comparándolos con los que conforman también otras prácticas sociales (militancia social, religiosa o política) que actúan sobre los problemas sociales, podemos afirmar que el componente teórico es el que le otorga particularidad a la profesión de Trabajo Social: el estudio, la formación sistemática y la argumentación teórica sobre los problemas que interviene. Las disciplinas de intervención trabajan con objetos teóricos y requieren contar con una teoría del objeto, porque, de lo contrario, actúan de manera empirista y ese lugar teórico pasa a ser ocupado por cualquier otro tipo de representación sobre el problema (tecnocrático o ideológico, por ejemplo).

Ahora bien, el proceso histórico de constitución disciplinar del Trabajo Social debe analizarse en juego dialéctico con los modos particulares en que las sociedades se organizaron para dar respuesta a los problemas sociales, entendidos como manifestaciones de la cuestión social, originada en las contradicciones fundantes del sistema capitalista, patriarcal y colonial.

Las concepciones teórico-metodológicas atraviesan transversalmente las diversas instituciones en cada contexto, hegemonizando un modo de interpretar lo social que marca también los debates al interior de este campo profesional. Las tendencias que han tenido fuerte incidencia en la formación profesional de los trabajadores sociales de nuestro país - y en particular en nuestra unidad académica - a lo largo de la historia del siglo XX han sido las teorías higienistas, la teoría estructural funcionalista, el movimiento - teorías y concepciones - liberacionista, la tendencia tecnocrática neoliberal y el enfoque de derechos humanos.

En este proceso histórico y en función del aspecto que estamos desarrollando - la construcción del campo disciplinar y la legitimidad profesional一, podemos señalar, como hito fundacional, la emergencia de las primeras instituciones de formación profesional del Trabajo Social entre los años $1925^{6}$ y 1930 en el Cono Sur. Se concluye así un campo

La primera Escuela de Servicio Social de América Latina se creó por iniciativa del médico Alejandro del Río, en 1925, en Chile, con una fuerte orientación paramédica y parajurídica y con un sello marcadamente femenino. 
profesional como exclusivo de algunos elegibles, utilizando el concepto de "clausura social" se ubican:

...procesos que se vinculan sobre todo a la dinámica interna de la constitución de elites. Abarcan por lo tanto la creación y consolidación de categorías de "elegibles" y sus opuestos, hecho que se relaciona de forma estrecha con la existencia o generación de un tipo determinado de escasez, que puede ser tanto de servicios o mercancías como de miembros de instituciones, asociaciones o grupos. (González Leandri, 1999, p. 123)

A lo largo de casi un siglo, el cuerpo de conocimientos considerado necesario y excluyente para la intervención profesional - y que lo diferenciaba de otras prácticas sociales, militantes, voluntaristas, caritativas- se fue consolidando en un proceso de debates y tensiones entre marcos teóricos instituidos e instituyentes, que tuvieron lugar centralmente en el seno de las instituciones formadoras de profesionales y en congresos y jornadas organizadas por los colectivos profesionales. Así, nos encontramos con distintos énfasis e incidencias en nuestra historia profesional que fueron puestas en juego y quedaron plasmadas en documentos, pronunciamientos, textos ${ }^{7}$; con miradas moralistas y normalizadoras, enfoques positivistas y desarrollistas, rupturas liberacionistas, perspectivas neoliberales y del marxismo-crítico, aperturas movimientistas y enfoque de derechos humanos, y que están presentes en un proceso instituyente, inacabado y conflictivo.

En este recorrido histórico, el problema de la especificidad del Trabajo Social se define por la forma en la que se articulan dialécticamente los elementos que lo constituyen (la ideología, la teoría y la técnica), en la que siempre alguno de los elementos resignifica a los

\footnotetext{
Múltiples estudios se han ocupado de la reconstrucción de estos debates en el Trabajo Social Latinoamericano. Solo para nombrar algunos de los más reconocidos y leídos, Netto, Iamamotto, Montagno y Faleiros en Brasil; Rozas, Carballeda, Siede y Parra en Argentina. En nuestro caso, en Córdoba, Argentina, el equipo de una cátedra de la asignatura Fundamentos y Constitución Histórica del Trabajo Social, desde 2004 en adelante está investigando procesos de la constitución histórica de la profesión, siendo el proyecto "Las concepciones sobre el Objeto de intervención del Trabajo Social en Argentina en los períodos desarrollista y reconceptualizador" el que ha iniciado esta línea de investigación y, en 2019, ha editado un libro que recoge las últimas investigaciones del equipo dirigido por Graciela Fredianelli y codirigido por Sabrina Bermúdez. El proceso de profesionalización del Trabajo Social en el Desarrollismo. Recuperado de https://rdu.unc.edu.ar/handle/11086/11038.
} 
otros. Así, desde la emergencia del Trabajo Social como disciplina, en la que la teoría articula a los otros dos elementos -ideología y técnica-, podemos afirmar que la técnica se convierte en tecnología, es decir, en acción científicamente fundada, y que el componente ideológico queda resignificado, ya que, si bien toda ciencia se construye enhebrada a una ideología, la ciencia le demanda a la ideología que se relativice, ejerciendo una sobre ella una "vigilancia epistemológica“ (Sánchez Vázquez, 1985). Lo ideológico tiene una función en la elección del problema y en la búsqueda de soluciones, pero en el análisis y en el conocimiento del problema la ciencia obliga a la ideología a reconocerse como una posición. Esto es al menos el "deber ser" de la ciencia, ya que la verdad absoluta no existe, existe la verdad relativa, y la tarea consiste en estar siempre construyendo la verdad, confrontando lo ideológico con el dato y con los efectos de la verdad que se pregona. Este énfasis en la articulación teórica marca fronteras con otras prácticas que no se reconocen como constitutivas del campo científico, ya que se mueven con otras reglas de juego, tales como los campos de la religión o de la política.

El segundo interrogante epistemológico sobre el campo disciplinar del Trabajo Social se vincula con la construcción de su objeto de intervención. El objeto del Trabajo Social está ubicado en el campo de las expresiones secundarias de las contradicciones fundantes del sistema -la cuestión social-, en el que tienen lugar los procesos de lucha por el acceso a satisfactores de necesidades para la reproducción cotidiana de la existencia, que son vedados o limitados a quienes ocupan un lugar de subalternidad en las relaciones de dominación que hemos nombrado.

Nuestra profesión emerge cuando la sociedad capitalista reconoce que la economía de mercado tiene fallas, cuando su forma organizativa muestra sus propias contradicciones, cuando el hecho objetivo de la pobreza y los problemas sociales están presentes también, como hechos subjetivos, en la conciencia pública. En el imaginario público crece la convicción de que la economía de mercado es insuficiente, se instala la idea de "justicia" como ideal público y el Estado y otras instituciones comienzan a intervenir con sus políticas públicas. Este imaginario se traduce en políticas públicas estatales o de la sociedad civil, ya que se considera que algo se debe y se puede hacer frente al problema. 
En la producción y reproducción de la existencia del sistema capitalista es posible identificar un campo de exclusiones y contradicciones que tienen un eje en la tensión capital-trabajo, como así también en la dominación sexista, patriarcal, colonial y extractivista. En la medida en que estas exclusiones dejan de ubicarse en el ámbito privado y pasan a ser preocupaciones en el imaginario público, se constituyen en objeto de políticas públicas.

El tercer problema epistemológico que nos proponía abordar el profesor Parisí se vincula con los dos anteriores (aquel proceso de casi un siglo de conformación del campo profesional del Trabajo Social en el Cono Sur y la definición del objeto específico del Trabajo Social): el alcance y la validez de los conocimientos científicos que componen el cuerpo teórico del Trabajo Social y la relación de éstos con la ideología.

Los planes de estudio de las carreras de Servicio Social en Argentina tienen en sus orígenes las bases teóricas de la medicina y de la abogacía, en un momento en el que estas profesiones reconocieron que la dimensión social resultaba imprescindible para alcanzar mejores estándares de salud para la población y mejor ordenamiento de la conflictividad social; en definitiva, en la búsqueda del control social, ambas. Vemos aquí el vínculo de tres profesiones: una naciente y otras dos con una larga trayectoria.

En el caso de Argentina, veinticinco años después, una nueva disciplina se incorpora en la formación universitaria, la Sociología, de la mano de Gino Germani y sus aportes acerca de los procesos de modernización y el análisis de sociedades tradicionales y modernas, y de los problemas sociales de la época; ello impacta en los planes de estudio del Servicio Social, que se abre al cuerpo de conocimientos de la ciencia social positivista, modelo hegemónico en ese momento. En ese mismo contexto, a mediados de la década del 50 se reorienta el modelo de desarrollo hacia una concepción que, en lo económico, intenta equilibrar los aspectos modernos y tradicionales (industria y agricultura) como mecanismo para superar las sociedades duales (tradicional-moderna/ marginal-desarrollada); en lo social y político, trata de integrar a las masas asalariadas y/o campesinas, sin modificar radicalmente la matriz societal existente (Ansaldi, 1997). Fue un periodo de desarticulación de la participación política de los sindicatos como interlocutores privilegiados, que se habían consolidado como actores 
políticos en el periodo peronista y que sentaron las bases para que, con el "desarrollista" Arturo Frondizi ${ }^{8}$, se inicie una etapa de incorporación masiva de los capitales extranjeros, mayoritariamente norteamericanos, de producción industrial de nuevos bienes intermedios, de consumo durable. En un contexto de Guerra Fría, esta injerencia de Estados Unidos no fue solo económica, sino también política, educativa y cultural. Así, las perspectivas sobre los problemas sociales y las estrategias de abordaje fueron teñidas del enfoque modernizador, de la planificación hacia el desarrollo que requería de una apertura al cambio. Ello impactó fuertemente en la revisión de los marcos conceptuales del Servicio Social, orientándose hacia perfiles de "agente de cambio" y de "promotor del desarrollo".

Confrontando con los enfoques positivistas y desarrollistas, el movimiento liberacionista ${ }^{9}$ de los años 1960 y 1970 introdujo marcos teóricos críticos, especialmente centrados en debates marxistas y liberacionistas, de la mano de la teoría de la dependencia, la educación popular y la investigación-acción, que fueron tomados por el movimiento de reconceptualización, revolucionando especialmente el modo de concebir al sujeto principal de la acción profesional en el Trabajo Social. Desde los 80, los procesos de recuperación democrática en América Latina resignificaron aquellos legados de la reconceptualización, instalando el debate y la producción respecto de la democracia, la vida cotidiana y las políticas sociales, y el lugar de la intervención profesional en dichos procesos. Los 90 estuvieron signados por la producción teórica que abordaba la tensión entre la consolidación de un nuevo tipo de Estado — el neoliberal- y las luchas de los nuevos movimientos sociales.

Este conjunto de marcos conceptuales fue dialogando con una práctica profesional que debía saber llegar a la cotidianeidad de un sujeto singular - pobre, marginado, explotado, dominado, subordina-

\footnotetext{
8 Arturo Frondizi (1908 - 1995) abogado, periodista, docente y político argentino, que fue elegido presidente de Argentina y gobernó entre el 1 de mayo de 1958 y el 29 de marzo de 1962, cuando fue derrocado por un golpe de Estado militar. Su gobierno estuvo caracterizado por un tipo de desarrollismo menos impulsado desde el Estado y más orientado al desarrollo de la industria pesada como consecuencia de la instalación de empresas multinacionales.

9 Ubicamos en esta corriente o movimiento a referentes tales como Paulo Freire, Orlando Fals Borda, Enrique Dussel, Pancho Aricó, entre otros
} 
do-, para establecer un vínculo desde el cual desarrollar procesos de acceso a satisfactores necesarios para su reproducción. Un saber hacer que, a lo largo de esos años, fue sistematizado, ordenado, normativizado, protocolizado, analizado, comparado, criticado y revisado; en definitiva, fue constituyendo un cuerpo de conocimientos sobre la intervención social, o teoría de la intervención.

Este proceso histórico nos muestra una relación dialógica mutuamente constitutiva entre conocimientos científicos y práctica profesional. Al respecto, acompañan nuestras afirmaciones los aportes de Roberto Follari (2016), quien se refiere al dilema impensado entre la ciencia y la profesión, diciendo que:

...la relación entre ciencia y práctica profesional no es una relación obvia, no es una relación de derivación según la cual, si ya tenemos lo que dice la ciencia, entonces en base a eso establecemos la práctica. Esta relación es bastante más complicada, porque en gran medida las prácticas eran anteriores a su justificación científica; y, por lo tanto, no es que las prácticas obedezcan necesariamente a lo que se planteó desde la ciencia. (Follari, 2016, p. 40)

Este sintético enunciado sobre casi un siglo de existencia de un campo profesional, pretende recuperar la rica conjunción de miradas profesionalistas, científicas e ideológicas que acompañaron el proceso de conformación de los conocimientos que hoy forman parte del Trabajo Social. Tal vez podríamos sintetizarlos en el reconocimiento que en nuestra región ha alcanzado el Trabajo Social como profesión y como área de conocimiento en el concierto de las ciencias sociales; siendo ésta ultima la que nos liga con la dimensión intelectual de la profesión, expresada en su capacidad de investigar la realidad y analizar los fenómenos como parte de la dinámica de lo real, produciendo un pensamiento crítico $^{10}$. Desde estas dos dimensiones - profesión y disciplina-, apostamos a trascender la condición de Trabajo Social como una práctica profesional destinada solo a intervenir y sistematizar su hacer, reivindicando e impulsando la producción de conocimiento como dimensión constitutiva de la profesión; consideramos

10 Tomamos estas ideas de Ana Elizabeth Mota, Los desafíos del trabajo social en la actual coyuntura latinoamericana -revista Conciencia Social Año XCI N 14 octubre del 2011 
que ello nos permitirá ejercitar una relativa autonomía teórica, práctica y política.

El campo disciplinar del Trabajo Social, por todo lo expuesto, forma parte legítimamente del campo de las ciencias sociales. Desde esta afirmación, fundada en la constitución histórica y los fundamentos epistemológicos del Trabajo Social, pasamos entonces a abordar los objetos de investigación y de intervención que nos caracterizan.

\section{Contextos de surgimiento de objetos de investigación y de intervención}

Hemos afirmado que el cuerpo de conocimientos que hoy reconocemos como aporte de la profesión de Trabajo Social, ha venido consolidando y legitimando la producción de conocimiento al interior de la misma. Si Trabajo Social puede ser definido como una práctica profesional de intervención y una disciplina de producción de conocimiento sobre lo social, entonces, $i$ es posible hablar de determinaciones cruzadas entre procesos de producción de conocimiento y procesos de intervención social? Esta será la pregunta que oriente el presente apartado.

La experiencia acumulada durante estos años nos permite afirmar que esta relación no es virtuosa en sí misma, sino una construcción de quienes ejercemos el oficio del Trabajo Social y que además no asume una sola forma. Es por demás aceptado que el problema de investigación se construye, que no constituye una relación en espejo de las preocupaciones iniciales de quienes se sienten insatisfechos con las respuestas ya dadas a un problema social. Existe cierto consenso (entre epistemólogos y metodólogos, en el marco de la una postura constructivista) en que las cuestiones que le interesan a las ciencias sociales, aun teniendo un claro anclaje en lo que genéricamente llamamos "realidad social", no se encuentran organizadas "espontáneamente" del modo en que las definimos y abordamos científicamente (Piovani, 2016, p. 50). Ya el clásico libro El oficio del Sociólogo, escrito por los franceses Bourdieu, Chamboredon y Passeron (1987), desarrollaba la idea de que el conocimiento no consiste en descubrir una realidad que está allí y se nos muestra de manera nítida, sino que debe ser construida, o mejor aún re-construida desde la óptica de la teoría. Los citados autores comienzan su reflexión epistemológica acerca de la construcción del objeto citando a Saussure, cuando afirmaba que el punto de vista crea el 
objeto, con la intención de señalar la necesidad de romper con el realismo ingenuo. Va de suyo que las categorías de sentido común, productos de los antagonismos en el espacio social, también están presentes en el campo científico, por lo cual no solo deben problematizarse las prenociones del mundo de la vida cotidiana, sino también aquellos presupuestos y preconstrucciones propios del sentido común erudito: la doxa del campo académico que se impone de manera prerreflexiva, como por ejemplo las distintas disciplinas, subdisciplinas y temáticas científicas, que nunca son divisiones intrínsecas de la realidad a estudiar. Adscribimos a esta definición del objeto de conocimiento como construcción y, aun en el reconocimiento del lugar central de la teoría, relativizamos también los tipos de conocimientos puestos en juego y su inacabada construcción.

Respecto de la necesidad de definición del objeto de intervención, un conjunto de colegas se ha explayado en eso; entre ellas especialmente Margarita Rozas y Nora Aquín. Para Margarita Rozas, la comprensión del objeto de intervención adquiere nueva significatividad desde la categoría de campo problemático; entendiendo que "el objeto de intervención se construye desde la reproducción cotidiana de la vida social de los sujetos, explicitada a partir de múltiples necesidades que se expresan como demandas y carencias, y que de esta forma llegan a las instituciones para ser canalizadas o no" (1998, p. 60). Uno de los aportes de Nora Aquín (2006), docente de nuestra casa de estudios, al corpus teórico de la profesión ha sido colocar el foco en fundamentar y desarrollar la cuestión del objeto de intervención, afirmando la necesidad de contar con una teoría del objeto, para no trabajar de manera empirista o desde cualquier otra representación.

Partimos de retomar los consensos que se han ido generando al interior de la profesión, respecto de que, tanto objeto de investigación como objeto de intervención, son construcciones y que, en esa construcción, algunas operaciones son similares y otras diferentes. Uno de los interrogantes que nos orientan es ¿cómo opera el contexto en el origen de las preocupaciones que orientan la intervención o que generan procesos de investigación?

Tomamos como referencia la clásica distinción entre contexto de justificación y contexto de descubrimiento. En filosofía de la ciencia, se llama "contexto de justificación" a las distintas pruebas, datos o 
demostraciones que el científico aporta para la justificación y defensa de la verdad de sus hipótesis ante la comunidad científica; en este contexto se incluyen los elementos y factores más propiamente científicos y racionales de la investigación científica. El "contexto de descubrimiento" se refiere a los factores que influyen en la creación de una teoría científica; hay que incluir elementos no estrictamente racionales o no estrictamente científicos (como los psicológicos, filosóficos, culturales, políticos, entre otros) que pueden influir en el éxito de una teoría ante la comunidad científica. La filosofía de la ciencia consideró durante mucho tiempo que el contexto de justificación era lo más interesante y fundamental para explicar el éxito de una teoría científica y su triunfo frente a teorías alternativas. A partir de los años sesenta, sin embargo, estará más atenta al estudio del contexto del descubrimiento, mostrando, cada vez más, la importancia de elementos y factores extracientíficos en el desarrollo y evolución de la ciencia. "El conocimiento no sólo es situado, sino que es terreno de innumerables disputas y tiene efectos constitutivos en el mundo. Un principio básico para orientar la agenda debe ser que lo que se investiga en una sociedad es lo que esa sociedad considera suficientemente importante" (Varsavsky, 1972, p. 56).

En este artículo nos referiremos al contexto de surgimiento como el entorno que rodea y en el cual se piensan, generan, imaginan, seleccionan y construyen los objetos tanto de intervención como de investigación. ¿Cómo se configuran y presentan los problemas de intervención? ¿Cómo se construyen los de investigación? ¿Cuáles preguntas nos hacemos y cuáles dejamos de hacer? ¿Cuál/es son las teorías imperantes en relación con el tema/problema y cuál su incidencia en la construcción e intervención sobre los mismos? En términos generales, el momento histórico, las acumulaciones desde la ciencia y el sentido común, la cultura y el habitus de quienes se interrogan, y desde qué lugares institucionales intervienen u operan, constituyen condiciones de posibilidad al proceso de conocimiento. Dice el Informe Wallerstein:

Ningún científico puede ser separado de su contexto físico y social. Toda medición modifica la realidad en el intento de registrarla. Toda conceptualización se basa en compromisos filosóficos. Con el tiempo, la creencia generalizada en una neutralidad ficticia ha pasado a ser un obstáculo importante al aumento del valor de ver- 
dad de nuestros descubrimientos. Y si eso plantea un problema a los científicos naturales, es aún mayor para los científicos sociales. (1996, p. 82)

Una primera cuestión entonces es que no hay producción de conocimiento aislada de sus condiciones de posibilidad, es imposible autonomizarnos del tiempo histórico en que pensamos y nos pensamos. Del mismo modo que es imposible abstraernos del contexto en que producimos, no hay intervención profesional que pueda definirse al margen del contexto (dinámico, frutos de tensiones y conflictos) ni al margen de lo que los agentes actúan; esto es así en tanto las profesiones no son categorías abstractas y ahistóricas, que puedan definirse de modo autónomo (Acevedo, 2016a y 2016b; Peralta, 2007). Con relación a esta cuestión y reflexionando acerca de los procesos de producción de conocimiento sobre juventudes, afirmábamos:

En un sentido amplio, ninguna investigación tiene un comienzo concreto; por el contrario, existen una serie de circunstancias, conocimientos y habilidades previas, que hacen más proclive que ciertas ideas florezcan en determinados ámbitos que en otros. La o las preguntas en cuestión, y las acciones que se derivan de ella, se gestan en un marco de relevancia, que es histórico, social, político y que reconoce acumulaciones individuales y colectivas. La investigación tiene lugar dentro de una comunidad científica, a la cual el investigador pertenece, y con la cual interactúa; es este proceso dinámico el que determina la relevancia y la pertinencia de las preguntas y las respuestas. (Acevedo, 2016a, p. 7)

Una segunda cuestión, fundada en los múltiples contactos, procesos de acompañamiento y formación a colegas, radica en la distancia que, a nuestro criterio, todavía existe entre procesos de intervención y procesos de investigación en términos generales, y más aún en la traducción de objetos de intervención en objetos de conocimiento. Hemos encontrado afirmaciones similares en un estudio de Hernández y Muñoz (Muñoz-Arce, Hernández-Mary y Véliz-Bustamante, 2017) en el cual, mediante el análisis temático categorial de 17 entrevistas con trabajadores/as sociales que se encuentran en la primera línea de ejecución de políticas sociales, los resultados indican que "aún persiste la comprensión del trabajo social como un quehacer eminentemente práctico. Sin embargo, también se identifican voces disidentes 
que comprenden la investigación como una estrategia que reafirma el compromiso del trabajo social con la emancipación".

Nos atrevemos a afirmar que hay una suerte de subutilización e invisibilización de información preexistente y producida desde la intervención del Trabajo Social, que aguarda ser convertida en dato. Una tercera cuestión es que, si bien ya no caben dudas de que investigación e intervención son dos dimensiones importantes y fundantes de la práctica profesional, aún es débil el lazo que existe entre las cuestiones que abordamos como problemas/objetos de intervención y su conversión en objeto de conocimiento. Nos referimos a los múltiples informes, formularios, registros de actividades que, en forma de grabaciones, fotos y afiches, recogen palabras, experiencias, prácticas, saberes propios y de los sujetos con y de la intervención, y que aguardan ser leídos, analizados, interpretados y puestos en circulación. Somos testigos, y en ocasiones también formamos parte, de este colectivo cuyo habitus está más ligado a la intervención y producción de saberes locales que a la posibilidad de la producción de conocimiento generalizable. Decíamos, en un artículo de nuestra autoría:

Quienes se acercan al equipo manifiestan no solo la inquietud de aprender a investigar, sino además a investigar con jóvenes y a enriquecer sus trabajos como estudiantes de grado y posgrado, como trabajadores de la educación y la cultura. Otro modo que asume la relación conocimiento e intervención está dada por los procesos de sinergia entre investigación y docencia; sin embargo, aún persiste la dificultad de la producción de conocimiento para su circulación más amplia. Probablemente esta dificultad se deriva de la tensión entre investigación e intervención, de larga data en el trabajo social. (Acevedo 2016, p. 20)

Construimos las afirmaciones precedentes a partir de observar que, si bien en los últimos años, desde los diversos espacios en que la profesión se ejerce, hemos incorporado de modo sistemático la lectura teórica, la referencia a investigaciones propias y de otras disciplinas en torno a los problemas sobre los cuales intervenimos, este proceso no es necesariamente así con relación a la riqueza que la intervención tiene como productora de posibles objetos de conocimiento. Podríamos afirmar que son prácticamente inexistentes los procesos de intervención al margen de fundamentaciones teóricas, de modo que no hay 
dudas de la relevancia que adquiere la teoría si pretendemos una intervención fundada; sin embargo, consideramos que no se reconoce aún el potencial de la intervención como fuente de posibles objetos de conocimientos. Desde los colegios profesionales, desde las especializaciones, maestrías y doctorados, desde los cursos de posgrado, ateneos, simposios y jornadas, los colegas que básicamente se dedican a la intervención en campo poseen un sinnúmero de interrogantes y advierten regularidades empíricas que surgen del contacto con la realidad. Sin embargo, puestos en situación de pensar temas de tesis, trabajos finales, artículos, investigaciones en servicio, se encuentran superados por la cantidad y dispersión de interrogantes; o prefieren realizar sus investigaciones o tesis en espacios fuera del ámbito laboral (afirmación realizada desde el reconocimiento del esfuerzo que supone combinar investigación e intervención, cuando las urgencias del accionar cotidiano están puestas en la resolución de problemas y necesidades).

Como toda regularidad empírica, la afirmación precedente presenta algunas excepciones, las que nos atrevamos a plantear como otra hipótesis. En el caso de la carrera de Licenciatura en Trabajo Social de la Universidad Nacional de Córdoba (UNC), desde la implementación de su último plan de estudios ${ }^{11}$ - que ya está pronto a ser revisado y actualizado-, la incorporación en el $\mathrm{V}$ año de la formación de una sustantiva carga horaria dedicada a la intervención preprofesional y a su sistematización constante, ha contribuido a que los estudiantes fortalezcan y potencien herramientas que les permitan integrar argumentaciones interpretativas, explicativas y propositivas en producciones sistemáticas.

En los diversos posgrados en que nos desempeñamos como docentes, observamos esta dificultad para ver un conjunto de potenciales problemas de investigación desde el ejercicio profesional. Atendemos a algunas explicaciones en relación con que:

...el punto crucial de la producción específica del Trabajo Social surge necesariamente en las intervenciones sociales, en el momento en el que el conocimiento del Trabajo Social se comunica con el saber de la práctica social; sin embargo, para ello se requiere que

$11 \quad$ Que se viene implementando desde 2006. 
los involucrados en el campo de la producción adopten una perspectiva de productor, independientemente de lo que quieran los consumidores, pues en ocasiones, los productores se dejan llevar por perspectivas ajenas a sus convicciones. (Heler, 2009, p. 8)

El aporte de Mario Heler nos invita a pensar acerca de nuestra relativa autonomía para indagar acerca de problemas que la profesión advierte, y lleva a preguntarnos sobre la incidencia de "otros" en la agenda de preocupaciones. Sin ninguna pretensión de autonomía absoluta, consideramos que revisar lo que hacemos y cómo lo hacemos desde lo que Estela Grassi (2011) llama "actitud investigativa", tal vez contribuya a adoptar la perspectiva de productor y no quedarnos solo con la de consumidores.

La cita de Mario Heler (2009) es una invitación a precisar desde dónde producimos en Trabajo Social y acerca de qué.

\section{Objetos de investigación y objetos de intervención: desde dónde y acerca de qué? Campos de producción de conocimientos que caracterizan al Trabajo Social}

Respecto de la relación entre objeto de investigación y objeto de intervención, podemos afirmar que la construcción del conocimiento nos permite ampliar las perspectivas de análisis del objeto de intervención; desde la intervención podemos plantearnos nuevos problemas de investigación y, mientras el proceso de investigación está guiado por la intención de conocer/comprender, el de la intervención lo está por la intención de cambiar/transformar.

Tratamos de responder a ¿qué investigamos los trabajadores sociales? ¿Por qué nos preocupan ciertos temas? ¿Qué es lo que caracteriza a nuestro campo y por lo tanto delimita los intereses desde los cuales hacemos intervención y hacemos investigación?

Hemos ubicado al objeto del Trabajo Social en el campo de los procesos de lucha por el acceso a satisfactores de los sujetos singulares con derechos vulnerados que afectan su propia reproducción cotidiana. La relación necesidades-satisfactores tiene lugar en los procesos de producción (y reproducción), distribución y consumo que ocurren de distintas maneras en todos los espacios de la vida social, y la especificidad del Trabajo Social se ubica en la compleja y 
conflictiva intersección entre tres esferas: la distribución secundaria del ingreso, los procesos de reproducción cotidiana de la existencia y los sujetos (con derechos vulnerados que generan) dificultades para atender, con sus propios medios, a las necesidades derivadas de su reproducción cotidiana (Aquín, 1995).

Este objeto - construido teóricamente- se aborda en un proceso dialéctico que se mueve entre tres dimensiones de análisis - general, particular y singular-, y que se recorre en uno y otro sentido permanentemente, tanto en los procesos de investigación como en los de intervención. Aquí, en este movimiento dialéctico, se construyen las mediaciones conceptuales necesarias para hablar de "praxis". Aquí se combinan las ideas abstractas con las observaciones empíricas y tiene lugar el proceso de producción de conocimiento.

Siguiendo a Pontes (1999), el proceso de conocimiento de la realidad es una totalidad cuyos complejos dinámicos están sometidos a una legalidad que resulta de sus propios procesos y que, si bien tiene un carácter de universalidad, se particulariza en cada complejo. Por ello:

la dialéctica entre lo general y lo singular se procesa a través de la particularidad, que, al decir de Luckaks, es un campo de mediaciones. En este campo de mediaciones es que los hechos singulares se vinculan con las grandes leyes de lo universidad y la universalidad se embebe de la realidad de lo singular. (1999, p. 5)

Desde esta misma preocupación, siguiendo a Muñoz, Hernández y Véliz (2017), podemos hablar de lógicas de procesos inductivos y deductivos en el análisis de estas dimensiones de la realidad, que se ponen en juego en el proceso de producción de conocimiento.

En los procesos de intervención, esa circulación entre las dimensiones tendrá un énfasis interesado en alcanzar la mayor profundidad analítica de la situación singular, para, desde allí, fundamentar principalmente argumentaciones propositivas. En los de investigación se perseguirá la mayor profundidad analítica de las dimensiones particular y/o general en las que se basarán las argumentaciones interpretativas y explicativas.

La posición desde la cual el Trabajo Social aborda su objeto teórico es la de intermediación entre el sujeto de necesidades-derechos vulnerados y el sujeto de recursos y satisfactores; permitiéndole esa 
intermediación captar, estudiar e intervenir en procesos, relaciones y prácticas sociales de por lo menos tres campos de conocimiento que surgen de las tres esferas en las que se define la especificidad del Trabajo Social.

Un campo se refiere a la cotidianeidad de la resolución de la reproducción social en ámbitos de la vida privada y su frontera con la vida pública: en esta vida cotidiana, aparentemente sin historia y sin razones, el sujeto apela a aquello con lo que cuenta para ponerlo en funcionamiento en el proceso de búsqueda de los objetos o satisfactores de su necesidad, que van más allá de los bienes económicos, ya que en estas estrategias los sujetos ponen en movimiento el volumen global del capital de que disponen, lo que incluye, además de su capital económico, el capital cultural y social. De lo que se trata en este campo es de prestar atención al sinnúmero de experiencias cotidianas por su reproducción: organizados o solitarios, apelando a los canales institucionales o renegando de ellos, con estrategias reproductoras del statu quo o rebelándose contra ellas, en contextos propiciatorios para la escucha o para la profundización de la exclusión. Sobre estas experiencias cotidianas Boaventura De Sousa Santos (2006) nos invita a sacudir la "modorra" y construir la Sociología de las Ausencias y de las Emergencias; nos propone "[intentar] una crítica a la razón indolente, perezosa, que se considera única, exclusiva y que no se ejercita lo suficiente como para poder mirar la riqueza inagotable del mundo" (De Sousa Santos, 2006, p. 20). Caracteriza a esta razón perezosa con dos rasgos fundamentales: por un lado, "fácilmente toma la parte por el todo", dejando fuera mucha realidades, muchas experiencias - o sea "lo diferente" tal como acabamos de señalar -; por otro, fácilmente se anticipa el futuro, "en el sentido de que ya sabemos cuál es el futuro: el progreso, el desarrollo de lo que tenemos; es un tiempo lineal que de alguna manera permite creer que el futuro es infinito" (De Sousa Santos, 2006, p. 21).

La intervención profesional nos pone en contacto con múltiples expresiones y ejemplos de toda la realidad que las políticas sociales dejan afuera, de todos los futuros que "no se quieren ver" en nombre de resolver el presente recortado. La vida cotidiana de los sujetos con los que trabajamos, los modos en que ponen en juego saberes y prácticas para la resolución de la reproducción social invitan a cuestionar 
interpretaciones teóricas lineales y generales. En cada espacio y tiempo, en cada práctica (familiar, social, colectiva), los sujetos apelan a estrategias y modos de resolver que en ocasiones solo se hacen visibles ante nuestras intervenciones. La capacidad-habitus-profesional con relación a la escucha, la recuperación de las prácticas y saberes populares, sin duda pueden (y deben, arriesgamos nosotras) volverse objetos y productos de conocimientos que superen la singularidad. El registro de prácticas y saberes locales y su conversión en problemas de investigación, sin duda son una potencialidad y una práctica posible de expandir. Apelar a los diversos modos de indagar y producir conocimiento (por caso la investigación acción participativa o la investigación militante) constituyen modos de potenciar la relación entre investigación e intervención.

Un segundo campo de conocimientos vinculado al Trabajo Social es el de la emergencia de las políticas sociales, en tanto producto de los procesos de lucha y politización de las necesidades que los sectores subalternos llevan adelante, irrumpiendo en la escena pública y cuestionando lo instituido. Nancy Fraser (1991) y Agnes Heller (1978), desde la filosofía política, eligen el concepto de "necesidades" como eje o foco de su desarrollo, lo que ha resultado un aporte teórico sustantivo para el Trabajo Social, ya que este concepto - "necesidades" - ha estado presente en los diversos marcos conceptuales y en los distintos momentos del proceso de constitución del campo. Nos interesa resaltar el carácter social y político de las necesidades y alejarnos de las concepciones positivistas o estructural- funcionalistas que resultaban en enfoques individualistas o pragmáticas de su abordaje. La acción rebelde o conformista de los sectores subalternos es definitoria en los procesos de lucha por las necesidades, en tanto confrontan e interpelan los límites de lo posible del aparato estatal y sus políticas. Los últimos años (al menos en nuestro país) están plagados de experiencias que abonan la idea de la instalación en la escena pública-política de temas y/o problemáticas por años ubicadas en el campo de la vida privada. La salud sexual y reproductiva, el medio ambiente (el derecho a vivir en poblaciones sanas, la resistencia a los agronegocios y la minería entre otros), el trabajo y la economía popular, las prácticas culturales colectivas y autogestivas, son algunos ejemplos de temas que, al decir de Nancy Fraser, 
vienen siendo instalados por los movimientos sociales, colectivos, y que, a fuerza de luchas y construcción de discursos, se instalan en la arena política. ¿Cuáles son los modos de organización de estos sectores? Cuál es el repertorio de acciones que utilizan, construyen? Quiénes deciden y cómo en estos espacios? ¿Cómo se configuran los discursos y cómo las prácticas? ¿Cuáles son las relaciones que se entablan con el poder político? Podríamos continuar con una larga lista de interrogantes que cotidianamente nos hacemos (incluso para algunos tenemos hipótesis, supuestos, respuestas posibles); sin embargo, como hemos venido sosteniendo, si bien es fuerte el lazo y la inserción del Trabajo Social en estas experiencias (en términos de intervención e incluso de militancia), aún es débil (o al menos podría ser más potente) la articulación en términos de convertir estos interrogantes en objetos de conocimiento. Tal vez debemos insistir en la importancia de las interpretaciones acerca de lo social, como un modo también de intervenir.

El tercer campo de producción de conocimientos que hemos identificado es el de la implementación de las políticas sociales y sus impactos en los sujetos. Dentro del estudio de las políticas sociales, con relación al lugar que ocupamos desde la intervención, viene bien llamar la atención sobre el campo de estudios de las políticas sociales desde la perspectiva de la implementación. La misma reconoce "al proceso de implementación como un objeto de conocimiento independiente, entendiendo que los actos, las prácticas y las rutinas administrativo-burocráticas hacen política pública y la modifican al intentar implementarla" (Chiara y Di Virgilio, 2005, p. 30). Ello permite abordar la complejidad de los procesos institucionales que se suceden entre el diseño y la evaluación, tanto como la diversidad de niveles y dispositivos de las estrategias de intervención.

El impacto de las políticas públicas en los sujetos de necesidades nos adentra en el mundo de la construcción de subjetividades y del concepto de "demanda efectiva", siguiendo a González (1999). Nos referimos a la noción acuñada por Marx para designar aquel tipo de demanda que tiende a las oportunidades objetivas de la satisfacción de la necesidad, inclinándose a vivir de acuerdo con las condiciones dadas, al mundo conocido y establecido, dentro del cual hay que ubicar: 
...aquellas necesidades que típicamente demandan los usuarios de los servicios a las instituciones del bienestar social: Dentro del cúmulo de necesidades insatisfechas, seleccionan las que se cubren con recursos que forman parte - según tiempo y lugar- del stock de satisfactores institucionalmente ofrecidos, y que de antemano saben que pueden demandar. (González 1999, p. 38)

En relación con las sinergias en el tercer campo identificado, sin dudas son múltiples los ejemplos con que cada uno de nosotros contamos. ¿Cómo impacta en los sujetos la implementación de las políticas? ¿Qué efectos tienen los criterios de selección y nominación en las dinámicas familiares y comunitarias? ¿Cuáles son los impactos coyunturales y qué cuestiones se sedimentan como experiencias, como marcas en la identidad? Nuestros registros tal vez están plagados de respuestas posibles a estos y otros interrogantes similares. Sin embargo, aún persiste la dificultad por convertir el dato en información generalizable o, más aún, por aprovechar las instancias de intervención también como instancias de investigación. No obstante, el panorama nunca es binario en estas cuestiones, de allí que, así como criticamos y nos criticamos como profesión, en relación con la aún débil articulación entre investigación e intervención, es solo desde la breve historia nuestra que podemos destacar las articulaciones que sí se vienen dando en la región. Solo a modo de ejemplo, que suponemos puedan encontrar similitudes en la región latinoamericana, citamos algunos de los proyectos que venimos desarrollando desde la carrera Licenciatura en Trabajo social de la UNC, y cuyos directores son profesionales de trabajo social: Intervención social en el campo educativo; Jóvenes, educación, trabajo y participación: Estrategias y circuitos de acceso que los jóvenes de sectores populares despliegan en contextos y tiempos de restricciones; La politicidad popular en las actuales condiciones de la reproducción cotidiana de los sujetos que viven del trabajo. Otros ejemplos los encontramos, como hemos mencionado en párrafos anteriores, en la proliferación de eventos específicos ligados a la investigación y en artículos y capítulos de libros. Asimismo, y refiriéndonos nuevamente a las experiencias nacionales, la inclusión en los nuevos planes de estudios no solo de asignaturas específicas de investigación, sino de tesinas finales con fuertes improntas en la producción de conocimiento, son muestras de las posibles articulaciones entre intervención e investigación. Tal vez los 
tiempos que vienen sean los de transformar el conocimiento científico en conocimiento que dispute en la arena pública interpelaciones acerca de lo social. Al conocimiento que se articula y en ocasiones es impulsado desde las preocupaciones de la intervención, debemos comenzar a pensar, ideas, imaginar modos y canales de hacerlo/convertirlo en conocimiento público.

En síntesis, tres campos problemáticos presentes en el objeto del Trabajo Social, atravesados por la dialéctica analítica de lo general, lo particular y lo singular, con énfasis en intervención o en investigación, nos marcan un espacio de diálogo fructífero al interior de la profesión y con las ciencias sociales.

\section{Conclusiones o invitaciones a seguir pensando}

Nuestras conclusiones apuntan a seguir pensando-nos.

En primer lugar, reafirmar que es posible ubicar al Trabajo Social en una doble inscripción: como disciplina en el marco de las ciencias sociales y como profesión de intervención fundada científicamente. Si pretendemos avanzar en la consolidación de esta doble inscripción, la construcción del campo disciplinar requiere que la investigación ocupe un lugar sustantivo y que la intervención se funde en recortes teóricos sobre los objetos que interviene. Para ello, es necesario identificar las diversas corrientes teóricas que han incidido y que forman parte del cuerpo de conocimiento del Trabajo Social, reconociendo su coexistencia y el encuentro con una práctica o saber hacer. Siguiendo a Follari (2016), dejar de subestimar nuestro origen como profesión de la mano del hacer, invirtiendo los polos de tensión que nos vienen atravesando desde hace casi un siglo, para recuperar el hacer y los saberes en torno al mismo y, desde allí, fortalecer y promover nuestra consolidación como campo disciplinario.

En segundo lugar, consideramos central resaltar la importancia de la noción de "contexto de surgimiento", en tanto permite desplazarse de la dicotómica postura planteada desde el modelo hegemónico de ciencia, cuando se refiere a contexto de descubrimiento y contexto de justificación. Lo que funda tanto a la investigación como a la intervención es la teoría (cuerpos teóricos preexistentes): entonces, podemos pensar en una relación sinérgica entre problemas de investigación y problemas de intervención. 
Un tercer aspecto sobre el cual es necesario llamar/nos la atención es la subutilización de información preexistente producida desde la intervención y que aguarda ser convertida en dato; la superación de este problema requiere de formación permanente, supervisión y una práctica sistemática de registro, sistematización y análisis.

El cuarto aspecto que queremos destacar es la importancia de los campos de conocimiento que hemos identificado. Vinculados a las esferas que definen la especificidad de esta profesión, son ordenadores u orientadores de búsquedas y precisiones teóricas, de diálogos interdisciplinarios y de formulación de preguntas de investigación, en las que el Trabajo Social tiene aportes significativos para el resto de las Ciencias Sociales.

Finalmente, la actitud profesional y científica necesaria es la de interrogarnos, mantener y profundizar nuestro inconformismo académico, reivindicando el planteo de Varsavsky (1960), quien propone pensar y definir la ciencia politizada como aquella vinculada con el compromiso social y dispuesta a revisar los parámetros desde los cuales se enseña. En tanto su quehacer no puede limitarse a lo contemplativo, sino que pretende ser también propositiva, la ciencia social politizada debería propender al diálogo como punto de partida y a la construcción de puentes de entendimiento. Producir ciencia social desde esta mirada supone la revisión y recuperación de los saberes y los conocimientos históricamente desconsiderados e invisibilizados. Así como el Trabajo social tiene la ductilidad de incorporar el contexto como parte constitutiva en las dimensiones investigativa e interventiva, así también posee la capacidad para la observación, el diálogo y la escucha con sectores excluidos, por historia hecha cuerpo, por lugar que ocupa nuestra práctica profesional en el sistema capitalista y por opción/es ideológicas; en general, nuestra práctica profesional se desarrolla con aquellos sectores subalternos, marginados e invisibilizados.

Ello requiere, siguiendo a Boaventura De Sousa Santos (2006), subvertir el conocimiento hegemónico, superando la razón indolente que subsume la comprensión del mundo a una única comprensión del mundo - la occidental - y condena a la no-existencia aquello que no se ajusta a sus premisas. Esta subversión epistemológica nos invita a revisar los objetos que definimos, los modos en que producimos co- 
nocimiento, los sujetos con quienes intervenimos y los productos de nuestro conocimiento.

\section{Bibliografía}

Acevedo, M. P. (2016a). Afectar lecturas y prácticas: Reconstrucción y relación entre investigación e intervención con jóvenes. Prácticas de oficio. Investigación y reflexión en Ciencias Sociales, 2(18), 1-12.

Acevedo, M. P. (2016b). Impedir que las ciencias sociales se desprendan del pensamiento crítico y que las profesiones se desprendan de miradas estratégicas. Ponencia en el III Foro Latinoamericano "Igualdad y desigualdad en América Latina: generando debates en Trabajo Social con las otras ciencias del campo social". La Plata.

Asociación Latinoamericana de Enseñanza e Investigación en Trabajo Social Alaeits. Propuesta Aprobada para la Articulación Latinoamericana de Trabajo Social. Recuperado de http://www. ts.ucr.ac.cr/html/alaeits/binarios/alaeits-documen-es-00001. pdf; Consulta 20 enero 2020

Ansaldi, W. y Funes, P. (1998). Viviendo una hora latinoamericana: Acerca de rupturas y continuidades en el pensamiento en los años veinte y sesenta. Cuadernos del CISH, 5, (Centro de Investigaciones Socio Históricas, Universidad Nacional de La Plata), La Plata (Argentina). Ponencia en el $1^{\text {er }}$. Encuentro Argentino-Chileno de Estudios Históricos (Mendoza, 9, 10 y 11 de noviembre de 1995) y en el XXI Congreso de la Asociación Latinoamericana de Sociología ALAS: América Latina y Caribe: por una democracia sin exclusiones ni excluidos (Sâo Paulo, Brasil, 31 de agosto a 5 de setiembre de 1997).

Aquín, N. (1995). Acerca del objeto del Trabajo Social. Acto Social, IV(10). Universidad Nacional de Córdoba.

Aquín, N. (2006). La investigación en el campo de Trabajo Social. En N. Aquín (coord.), Reconstruyendo lo social. Prácticas y experiencias de investigación desde el Trabajo Social (pp. 9-20). Buenos Aires: Espacio Editorial.

Aquín, N. (2000). Disertación Colegio de Profesionales en Servicio Social de la provincia de Buenos Aires, distrito La Plata, agosto.

Aquín, N. (1996). La relación sujeto-objeto en Trabajo Social: Una resignificación posible. En FAUATS (comp.) La especificidad 
del Trabajo Social y la formación profesional (pp. 67-82). Buenos Aires: Espacio Editorial.

Bourdieu, P, Chamboredon J. C. y Passeron J. C. (1987). El oficio del sociólogo. México: Siglo XXI.

Chiara, M. y Di Virgilio M. M. (org.). (2005). Gestión de la política social. Conceptos y herramientas. Buenos Aires: Editorial UNGS.

De Sousa Santos, B. (2006). Renovar la teoría crítica y reinventar la emancipación social. Buenos Aires: CLACSO.

Follari, R. (2016). Teoría científica y práctica profesional: relaciones no lineales e imprescindibles. Revista Pilquen, 13(2), 39-47.

Follari, R. (2000). Epistemología y Sociedad. Acerca del debate contemporáneo. Rosario: Homo Sapiens Ediciones.

Fraser, N. (1991). La lucha por la interpretación de las necesidades: esbozo de una teoría crítica socialista-feminista de la cultura política del capitalismo tardío. Revista Debate Feminista, 3, $3-40$.

González, C. et al. (1999). Informe Proyecto de Investigación de la Cátedra de Trabajo Social con Familias. Córdoba: ETS-UNC.

González, C. (2007) Reflexiones en torno a la intelectualidad y a las prácticas sociales, en Trabajo Social, prácticas universitarias y proyecto profesional crítico. I Encuentro Argentino y Latinoamericano. ETS-UNC y Colegio de Profesionales en Servicio Social de la Provincia de Córdoba.

González Leandri, R. (1999). Las profesiones, entre la vocación y el interés corporativo. Madrid: Editorial Catriel.

Grassi, E. (2011). La producción en investigación social y la actitud investigativa en el Trabajo Social. Revista Debate Público. Reflexión de Trabajo Social, 127-139.

Grassi, E. (2007). Problemas de realismo y teoricismo en la investigación social y en el Trabajo Social. Revista Katál - Florianópolis, 10 ( No especial), 26-36.

Grüner, E. ( 2006) Lecturas culpables. Marx(ismos) y la praxis del conocimiento, en Borón A., Amadeo, J y González S., La teoría marxista hoy. Problemas y perspectivas, Buenos Aires: Editorial CLACSO.

Heler, M. (2009). El problema del posicionamiento de la producción del campo profesional del Trabajo Social. Buenos Aires: Cátedra UBA. 
Heller, A. (1978). Teoría de las necesidades en Marx. Barcelona: Editorial Península.

Iamamoto, M. (1997). Servicio Social y División del Trabajo. San Pablo: Cortez Editora.

Iamamoto, M. ( 2003). El Servicio Social en la contemporaneidad. San Pablo: Cortez Editora.

Kosic, K. (1965). Dialéctica de lo concreto. México: Editorial Grijalbo.

Muñoz-Arce, G., Hernández-Mary, N. y Véliz-Bustamante, C. (2017). La relación entre investigación e intervención social: voces desde el trabajo social chileno. Trabajo Social Global - Global Social Work. Revista de Investigaciones en Intervención social, 7(12), 3-24.

Parisí, A. (1993). Paradigmas teóricos e intervención profesional. Córdoba: Mimeo del Departamento de Investigación de la Escuela de Trabajo Social de la Universidad Nacional de Córdoba.

Parra G. (2020). El Objeto y el Trabajo Social. Algunas aproximaciones a la problemática del objeto en el Trabajo Social. Cuadernillo Desde el fondo. Recuperado de http://www.fts.uner. edu.ar/publicaciones/publicaciones/desde_el_fondo/pdf/ Nro_15/7\%20Parra\%2015.pdf

Peralta, M. I. (2007). Disertación en Panel: "Producción del conocimiento en el ejercicio profesional". Congreso FAPSS. Mendoza.

Piovani, J. I. (2016). Reflexiones sobre el proceso de investigación social. En Gallegos, C., Mejía Martínez, E. A. y Paredes Vilchiz, Y. (coord. ), ¿Cómo investigamos? ¿Cómo enseñamos a investigar?, tomo IV, México: Universidad Nacional Autónoma de México.

Pontes, R. N. (1999). A categoria de mediação em face do processo de intervenção do Serviço Social, Boletín Electrónico Surá. Escuela de Trabajo Social. Universidad de Costa Rica.

Sánchez Vázquez, A. (1985). Ensayos de marxistas sobre historia y política. México: Editorial Océano.

Varsavsky, O. (1960). Ciencia, política y cientificismo. Buenos Aires: Centro Editor de América Latina.

Véliz Bustamante, C. y Andrade Guzmán, C. (2017). Formación en Trabajo Social: articulaciones entre investigación e intervención y estrategias de enseñanza aprendizaje. Revista Latinoamericana de Metodología de la Investigación Social 7(14), 51- 
64. Recuperado de http://www.relmis.com.ar/ojs/index. $\mathrm{php} / \mathrm{relmis} /$ article/view/184

Wallerstein I. (coord.). (1996). Abrir las Ciencias Sociales. Informe de la comisión Gulbenkian para la reestructuración de las ciencias sociales. México: Siglo XXI Editores. 